\title{
Health Promotion Centres in urban Nepal: two major questions and a fitting solution
}

\author{
Sudesh Raj Sharma ${ }^{1,2}$ \\ ${ }^{1}$ Nepal Development Society, Nepal ${ }^{2}$ College of Health, Massey University, NZ
}

\section{Received:}

14 March 2017

Revised:

21 September 2017

\section{Accepted:}

5 November 2017

\section{${ }^{\star}$ Correspondence:}

yoursudesh@gmail.com College of Health, Massey University, NZ
Health Promotion Centres (HPCs) are being opened up in Kathmandu district particularly to deal with non-communicable diseases (NCDs) through preventative actions (1). This is a good step towards addressing an impending pandemic which needs sustained support and rapid scale up to cover majority of urbanites gradually extending to rural population as well. NCDs prevalence is on rapid rise in both urban and rural areas due to lifestyle and environment related influences (2-4). These HPCs mainly aim to provide screening services of key NCD metabolic risks (high BP, high sugar and high cholesterol), refer at risk patient, disseminate information relating to prevention of such risks and conduct inspection of local eateries (1). The objective of this letter is to raise two major questions and propose one fitting solution towards improving the effectiveness of such HPCs.

First question that arises is how well are these centres equipped to help change behaviours of those who seek their support? In other words, do we have resources to run such centres effectively? The government should be able to equip such centre with much needed resources such as behaviour change communication (BCC) materials (poster, brochures, pamphlets, pocket booklets, etc.), screening equipments and kits and adequate skilled human resources for quality services. Most importantly, we may need a dedicated and reliable website in Nepali having information about the causes, prevention and treatment of major NCDs for the use by both health promoters and general public. Such websites are readily available in developed countries context through both public and private sectors (5-7). The Heart Foundations in both Australia and New Zealand are regularly disseminating evidence based information aimed at both general public and health professionals for heart health promotion through their websites $(6,8)$. Centre for Disease Control of the US government is another resourceful website. Further, related information on World Health Organization website is more relevant to developing countries context (9). There is huge opportunity to transfer such readily available information relating to NCDs prevention relevant to our context. In this era of information technology, telephone based counselling and mobile apps to support quitting smoking and alcohol and initiating healthy diet can be handy for those with access to mobile/smart phones. Such approach is being successfully applied in developed countries $(10,11)$. Alternatively, tracking chart with milestones (for quitting smoking/alcohol or weight loss or physical activity, etc.) and pictorial information booklet would be needed to those who are illiterate and/or may not have access to mobile phones along with ensuring support from family members.

Second major question that comes up is what role and authority would the health promotion staffs have in monitoring restaurants and eateries for food quality (including storage, handling and hygiene) as well as shops that sell cigarette and tobacco? Are they able to rank and/or penalize restaurants based on their food handling and hygiene practice? Is there a personal safety risk to such monitoring staffs? Monitoring of restaurants is much needed for ensuring better food handling and hygiene practice for food quality while monitoring of shops would ensure systematic and lawful sales of tobacco and alcohol.

One fitting solution to address those two questions would be collaboration between the District Public Health Office, Kathmandu and non-government sector (community based organizations, professional organizations and academia) and utilizing the experience of the latter in addressing NCDs, platform being such HPCs. There are many non-government organizations (NGOs) and young professionals who are skilled and motivated to strengthen such health promotion centres in the areas of BCC materials development, website development, training and knowledge management, phone based counselling and support and "mobile app" development. BCC campaigns led by the District Public Health Office, Kathmandu and the National Health Education Information and Communication Centre should align and utilize this partnership to reach the unreached with key messages relating to NCD prevention and health promotion. Further, a joint committee involving community based organizations, local leaders and government officials from HPCs, municipality and food quality monitoring office for strictly monitoring local eateries, restaurants and shops once every month would be safer and sustainable. This community based approach is both strategic and empowering in the current volatile socio-political situation of Nepal.

Most importantly, the health promotion workers within HPCs should be continually supported and motivated by the policy sphere for community based actions because fighting NCDs and its social determinants warrant long term and community based efforts and resources. The health leaders should 
understand that the effect of such centres will not be apparent in few months or even years and should be patient to reap the benefits. Those centres should be timely and adequately resourced at all times. What is now urgently needed is an open call by the government to the NGOs, private sector, professionals and local stakeholders for supporting this initiative.

\section{References}

1. The Kathmandu Post. MoH to set up 10 urban health promotion centres Nepal: The Kathmandu Post (Online); 2016 [Available from: http://kathmandupost. ekantipur.com/news/2016-12-22/moh-to-set-up-10-urban-health-promotion-centres.html.

2. Dhungana RR, Devkota S, Khanal MK, Gurung Y, Giri RK, Parajuli RK, et al. Prevalence of cardiovascular health risk behaviorz in a remote rural community of Sindhuli district, Nepal. BMC cardiovascular disorders. 2014;14:92.

3. Vaidya A, Pathak RP, Pandey MR. Prevalence of hypertension in Nepalese community triples in 25 years: a repeat cross-sectional study in rural Kathmandu. Indian heart journal. 2012;64(2):128-31.

4. Aryal KK, Mehata S, Neupane S, Vaidya A, Dhimal M, Dhakal P, et al. The burden and determinants of non communicable diseases risk factors in Nepal: findings from a nationwide STEPS survey. PloS one. 2015;10(8):e0134834.

5. Australian National Preventive Health Agency. Overweight and obesity prevention 2013 [Available from: http://quitnow.gov.au/internet/anpha/publishing.nsf/ Content/obesity-home.

6. Heart Foundation. Resources New Zealand: Heart Foundation, NZ; 2016 [Available from: https://www.heartfoundation.org.nz/r zzsources/.

7. Centers for Disease Control and Prevention. Noncommunicable Diseases: Resources USA: U.S. Department of Health and Human Services; 2016 [Available from: https://www.cdc.gov/globalhealth/healthprotection/ncd/resources/index.html.

8. Heart Foundation. Your heart Australia: Heart Foundation, AU; 2016 [Available from: https://heartfoundation.org.au/support zhealth-information-service.

9. World Health Organization. Non-communicable diseases: WHO; 2015 [Available from: http://www.who.int/mediacentre/factsheets/fs355/en/.

10. Department of health. MY QUITBUDDY Australia: Australian Government; 2015 [Available from: http://www.health.gov.au/izternet/quitnow/publishing.nsf/ Content/quit-buddy.

11. Heart Foundation. Health Information Service Australia: Heart Foundation, AU; 2016 [Available from: https://heartfoundation.org.au/support/healthinformation-service. 